\title{
Biologia reprodutiva de Miconia angelana (Melastomataceae), endêmica da Serra da Canastra, Minas Gerais ${ }^{1}$
}

\author{
ANA PAULA MILLA DOS SANTOS 2,3 , ROSANA ROMERO² e \\ PAULO EUGÊNIO A. M. DE OLIVEIRA ${ }^{2}$
}

(recebido:07 de agosto de 2008; aceito: 23 de abril de 2010)

\begin{abstract}
Reproductive biology of Miconia angelana (Melastomataceae), endemic from Serra da Canastra, Minas Gerais). The reproductive biology of M. angelana R. Romero \& R. Goldenberg was studied by controlled hand pollinations, pollen viability, pollen tube growth and seed germination. Miconia angelana flowered in late October and early November, presented self-compatibity and was independent of buzz pollination. The autogamy, facilitated by the two large pores of the anthers and stamens symmetrically disposed around the style, was responsible for the high fruit-set (91.5\%) and high seed germination (92\%). Miconia angelana is one of the five species of Melastomataceae reported for autogamy and one of the five of the Miconia genus with nectar production that, together with the awkward odor exhaled by the flowers, makes possible a higher variety of floral visitors as moths, wasps, flies, ants, beetles and bees with vibratory behavior or not.
\end{abstract}

Key words - endemism, Melastomataceae, Miconia angelana, nectar

RESUMO - (Biologia reprodutiva de Miconia angelana (Melastomataceae), endêmica da Serra da Canastra, Minas Gerais). A biologia reprodutiva de $M$. angelana R. Romero \& R. Goldenberg foi estudada por meio de polinizações controladas, viabilidade polínica, crescimento do tubo polínico e germinação de sementes. Miconia angelana floresce entre o final de outubro e o início de novembro, é autocompatível e independente de polinização vibrátil. A autogamia, facilitada pela presença de anteras com dois poros que facilitam a saída do pólen sem que haja vibração e estames dispostos simetricamente ao redor do estilete, foi responsável pelas maiores porcentagens de frutificação (91,5\%) e germinação das sementes (92\%). Miconia angelana é uma das cinco espécies de Melastomataceae conhecidas até o momento que apresenta frutificação a partir de autopolinização espontânea e uma das cinco espécies do gênero Miconia com produção de néctar, que juntamente com o odor desagradável das flores, possibilita uma maior variedade de visitantes florais como mariposas, vespas, moscas, formigas, besouros e abelhas com comportamento vibratório ou não.

Palavras-chave - endemismo, Melastomataceae, Miconia angelana, néctar

\section{Introdução}

A xenogamia é bastante comum entre as plantas lenhosas do Cerrado, principalmente devido à frequência de espécies autoincompatíveis ou dióicas, nas quais a polinização cruzada é praticamente obrigatória (Oliveira \& Gibbs 2000). Na maioria das espécies de Melastomataceae, esse sistema reprodutivo é facilitado pela separação espacial entre o estigma e o pólen nas flores (hercogamia) e pela presença de anteras poricidas, que necessitam ser fortemente vibradas para liberação do pólen (Renner 1989). Entretanto, trabalhos recentes têm mostrado a presença de espécies autocompatíveis e apomíticas na família (Goldenberg \& Shepherd 1998,

1. Parte da dissertação de mestrado da primeira autora, Programa de Pós-Graduação em Ecologia e Conservação de Recursos Naturais da Universidade Federal de Uberlândia, Uberlândia, MG, Brasil.

2. Universidade Federal de Uberlândia, Instituto de Biologia, Caixa Postal 593, 38402-020 Uberlândia, MG, Brasil.

3._Autora para correspondência: anapmilla@yahoo.com.br
Melo et al. 1999, Goldenberg \& Varassin 2001, Fracasso \& Sazima 2004).

Em cerca de 98\% das espécies de Melastomataceae, o pólen é o único recurso oferecido, sendo de extrema importância para as abelhas tropicais (Renner 1989). Geralmente, sua retirada só é possível por meio de polinização vibrátil (buzz pollination), resultado de uma longa história de coevolução e adaptação planta-polinizador (Buchmann 1983, Proença 1992).

Entretanto, algumas espécies de Miconia, principalmente das seções Cremanium, Hypoxanthus e Glossocentrum, são mais generalistas quanto ao sistema de polinização quando comparadas às demais espécies da família. Por possuírem flores pequenas em densas inflorescências e anteras com poros grandes, espécies como M. hyemalis A. St.-Hil. \& Naudin, M. pusilliflora (DC.) Naudin e M. pepericarpa Mart. ex DC. podem ser polinizadas tanto por abelhas de médio e grande portes que vibram a inflorescência inteira, como por pequenas abelhas, sem comportamento vibratório, que não teriam sucesso na polinização de flores maiores (Goldenberg et al. 2008). 
A produção de néctar é rara na família e, quando ocorre, também permite uma variedade maior de polinizadores além das abelhas, como moscas (Goldenberg \& Shepherd 1998), morcegos, beija-flores (Renner 1989) e roedores (Lumer 1980). Destas, a polinização por roedores é a mais rara, conhecida apenas para três espécies de Blakea da Costa Rica, nas quais a antese e a produção de néctar são noturnas (Lumer 1980, Lumer \& Schoer 1986).

A família Melastomataceae está entre as seis maiores famílias de Angiospermas do Brasil, com mais de 1.500 espécies e 160 gêneros (Clausing \& Renner 2001). O gênero Miconia, com cerca de 1.050 espécies, ocorre em toda a América Latina, principalmente ao longo da Cordilheira dos Andes, e se estende ao Norte da América do Sul e ao Sudeste brasileiro (Goldenberg 2000). A maioria das espécies de Miconia estudadas até o momento é apomítica ou autoincompatível, mas pouco se sabe sobre a reprodução das espécies endêmicas, que representam quase 50\% do gênero (Goldenberg \& Shepherd 1998, Goldenberg 2000).

A região da Serra da Canastra é conhecida pela diversidade de espécies e pelo alto grau de endemismo, com cerca de 50 espécies endêmicas, das quais nove são de Melastomataceae (Romero \& Nakajima 1999, Romero \& Martins 2002). Miconia angelana, uma destas espécies, ocorre apenas na região da nascente do Rio São Francisco, em solo úmido e rochoso (Romero \& Goldenberg 1999). O presente trabalho teve como objetivo estudar a biologia reprodutiva de Miconia angelana R. Romero \& R. Goldenb. (Melastomataceae) de forma a entender a regeneração natural da espécie e subsidiar ações de conservação.

\section{Material e métodos}

O trabalho de campo foi realizado entre novembro de 2006 e dezembro de 2007 no Parque Nacional da Serra da Canastra, envolvendo duas estações de floração. O Parna Serra da Canastra é a segunda maior unidade de conservação de Minas Gerais, e abrange os Municípios de São Roque de Minas, Delfinópolis e Sacramento, a sudoeste do estado. Com uma área de 200.000 ha, o Parque está localizado entre as latitudes $20^{\circ} 00^{\prime}$ a $20^{\circ} 30^{\prime} \mathrm{S}$ e longitudes $46^{\circ} 15^{\prime}$ a $47^{\circ} 00^{\prime} \mathrm{W}$. O clima regional é caracterizado pela sazonalidade, sendo o trimestre de novembro a janeiro, o mais chuvoso (figura 1). A vegetação é formada principalmente por campo rupestre presente nas áreas de maior altitude, as quais podem chegar a $1.500 \mathrm{~m}$ No Parque também são encontradas outras fitofisionomias de Cerrado, como matas de galeria, florestas mesófilas de encosta, capões, campo cerrado e campo limpo (MMA/Ibama 2005).

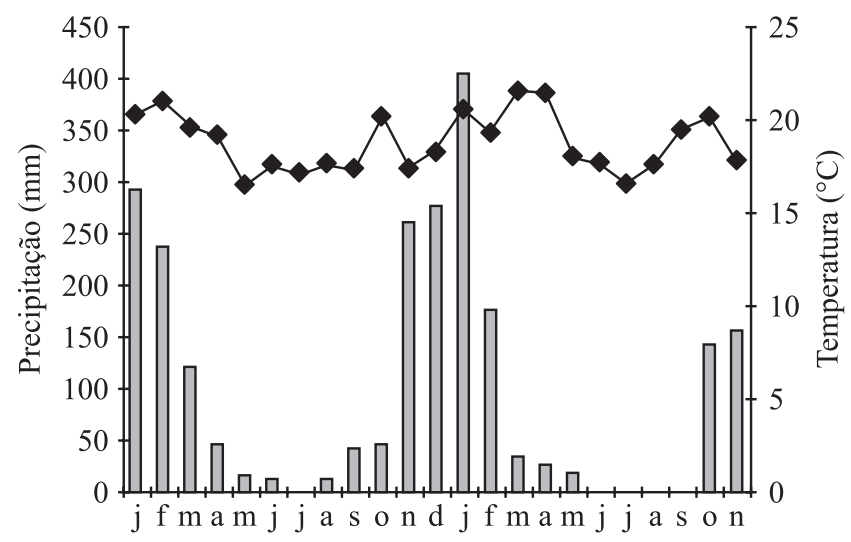

Figura 1. Temperatura média mensal e precipitação acumulada mensal no Parque Nacional da Serra da Canastra, Minas Gerais, no período de janeiro de 2006 a novembro de 2007 (fonte: Laboratório de Climatologia e Recursos Hídricos - UFU). ( $\square=$ precipitação (mm); $\neg-$ temperatura $\left({ }^{\circ} \mathrm{C}\right)$ ).

Figure 1. Monthly average temperature and accumulated monthly precipitation in the Parque Nacional da Serra da Canastra, Minas Gerais, from January 2006 to November 2007 (source: Laboratório de Climatologia e Recursos Hídricos - UFU). ( $\square=$ precipitation $(\mathrm{mm}) ;-\bullet-=$ temperature $\left({ }^{\circ} \mathrm{C}\right)$ ).

Aspectos da biologia reprodutiva de M. angelana foram descritos por meio de observações sobre características morfológicas, fases de floração e frutificação, horário e sequência da antese, duração da flor, emissão de odores e produção de néctar.

A concentração de açúcares e o volume de néctar produzido foram medidos, respectivamente, com o auxílio de um refratômetro de bolso e de um capilar de $1 \mu \mathrm{L}$. As medições foram feitas em 50 flores previamente ensacadas com organza, a fim de evitar o contato com polinizadores.

Os visitantes florais foram capturados e fotografados, quando possível, durante cinco dias, totalizando 30 horas de observações. Insetos capturados e fotografias foram utilizados para identificação dos visitantes. Material botânico testemunho foi também coletado e encontra-se depositado no Herbarium Uberlandense (HUFU 47.570).

O sistema reprodutivo foi estudado por meio de polinizações controladas em flores recém-abertas ou em pré-antese, de 10 indivíduos diferentes. Os tratamentos envolveram: autopolinização espontânea (flores isoladas por sacos de organza e não manipuladas), autopolinização manual (flores polinizadas com o próprio pólen ou pólen de outras flores do mesmo indivíduo também isoladas desde a pré-antese), polinização cruzada (flores isoladas em préantese e polinizadas com flores de outros indivíduos da mesma população), teste para apomixia (emasculações, na fase de pré-antese, de botões previamente isolados) e flores apenas marcadas e mantidas sob condições naturais (controle) (adaptado de Radford et al. 1974). A taxa de 
frutificação foi verificada após dois meses da realização dos tratamentos.

A viabilidade polínica foi estimada a partir do pólen de 20 botões em pré-antese, fixados em etanol a 70\%. A coloração do citoplasma com carmim acético e a morfologia do grão de pólen foram usadas como critério de avaliação da viabilidade polínica (Kearns \& Inouye 1993).

O crescimento de tubos polínicos foi observado em estiletes de flores fixadas em três intervalos de 24 horas após autopolinização manual e polinização cruzada. Os estiletes foram corados com azul de anilina e observados em microscopia de fluorescência (Martin 1959). Uma amostra de flores submetidas à autopolinização espontânea ( $n=60)$ também foi analisada quanto à presença de tubos polínicos.

As sementes provenientes dos frutos formados após os tratamentos de polinizações controladas foram colocadas em câmaras de Emanuelli, sob luz branca fluorescente contínua à temperatura média de $25^{\circ} \mathrm{C}$, a fim de testar sua capacidade de germinação. Para os tratamentos de autopolinização espontânea, autopolinização manual, polinização cruzada e controle, foram montadas cinco repetições com 30 sementes cada. A leitura das amostras foi feita diariamente, considerando-se germinadas as sementes que apresentavam protrusão da radícula. O experimento foi encerrado após dois meses consecutivos sem germinação e as sementes restantes foram abertas para verificar a presença de embrião. Com os dados de germinação calculou-se a germinabilidade e o tempo médio de germinação (Labouriau 1983, Ranal \& Santana 2006).

Após 50 dias, foram medidos a raiz primária e o hipocótilo de 20 plântulas de cada tratamento. Os resultados de germinação e o crescimento inicial das plântulas foram submetidos aos testes de normalidade de Shapiro-Wilk, homogeneidade de Levene (F), ANOVA ou Kruskal-Wallis, seguidos de Tukey ou Dunn, respectivamente.

\section{Resultados}

A população $M$. angelana estudada possui cerca de 30 indivíduos arbustivos com até $2 \mathrm{~m}$ de altura, que ocorrem bem próximos uns dos outros em solo úmido, às margens do rio São Francisco (figura 2). A floração foi rápida e massiva com duração aproximada de três semanas, entre o final de outubro e início de novembro, sendo mais intensa nos dias que sucederam períodos de chuva. A antese é diurna, espalhada ao longo do dia. As flores duram cerca de dois dias e exalam um odor forte e desagradável.

As flores actinomorfas medem 4-5 mm de diâmetro estando dispostas em inflorescências de glomérulos terminais com 7-15 cm de comprimento (figura 3). O cálice, a corola, o gineceu e os 10 estames isomorfos, dispostos simetricamente ao redor do estilete, são de cor creme. As anteras, com ca. de $15 \mathrm{~mm}$ de comprimento, possuem dois poros grandes e apicais, liberando facilmente o pólen seco e pulverulento. Com pequenos movimentos na inflorescência o pólen é rapidamente liberado formando, por alguns segundos, uma nuvem branca em torno das flores.

Apenas as flores de primeiro dia apresentaram pequenas quantidades de néctar acumulado na porção superior do hipanto. O volume total de néctar coletado em nove flores foi de $2 \mu \mathrm{L}$, com concentração de açucares em torno de $7 \%$.

Os frutos do tipo baga, com até $1 \mathrm{~cm}$ de diâmetro, arroxeados a nigrescentes quando maduros permaneceram na planta durante toda a estação chuvosa, até meados de maio (figura 4).

Em 30 horas de observação foram encontrados vários visitantes florais (figura 5-10), como mariposas das famílias Actiidae e Sphingidae (Aellopos sp.), vespas (Polistes sp.), moscas, formigas (Camponotus sp.), besouros e abelhas com comportamento vibratório (Eulaema sp., entre outras) ou não (Apis mellifera).

Os resultados das polinizações controladas mostraram que $M$. angelana é autocompatível (tabela 1). Apenas dois frutos formados pelo tratamento de emasculação do botão floral (teste para apomixia) chegaram à maturação, mas apresentaram sementes viáveis. A formação de frutos por polinização cruzada predominou em relação à autopolinização manual, apresentando ISI (sensu Bullock 1985) de 0,53. Entretanto, o tratamento com maior frutificação foi o de autopolinização espontânea (91,5\%).

A porcentagem de viabilidade polínica, estimada por coloração, para os indivíduos de $M$. angelana foi alta $(94,6 \pm 3,9)$.

Os tubos polínicos, observados em microscopia de fluorescência, não apresentaram reações de autoincompatibilidade ao longo do estilete, mas houve diferença na velocidade de crescimento. Os tubos polínicos observados em estiletes submetidos ao tratamento de autopolinização manual alcançaram o ovário após 48 horas, sendo cerca de 24 horas mais lentos em relação ao tratamento de polinização cruzada.

Tubos polínicos foram verificados em 75\% dos pistilos das flores submetidas ao tratamento de autopolinização espontânea $(n=46)$, mas não foi possível avaliar a velocidade de crescimento de tubos polínicos nesse tratamento.

Os experimentos de germinação mostraram sementes viáveis independente do tipo de polinização (tabela 1). Contudo, houve diferença entre os tratamentos quanto à germinabilidade, que foi maior nas sementes 

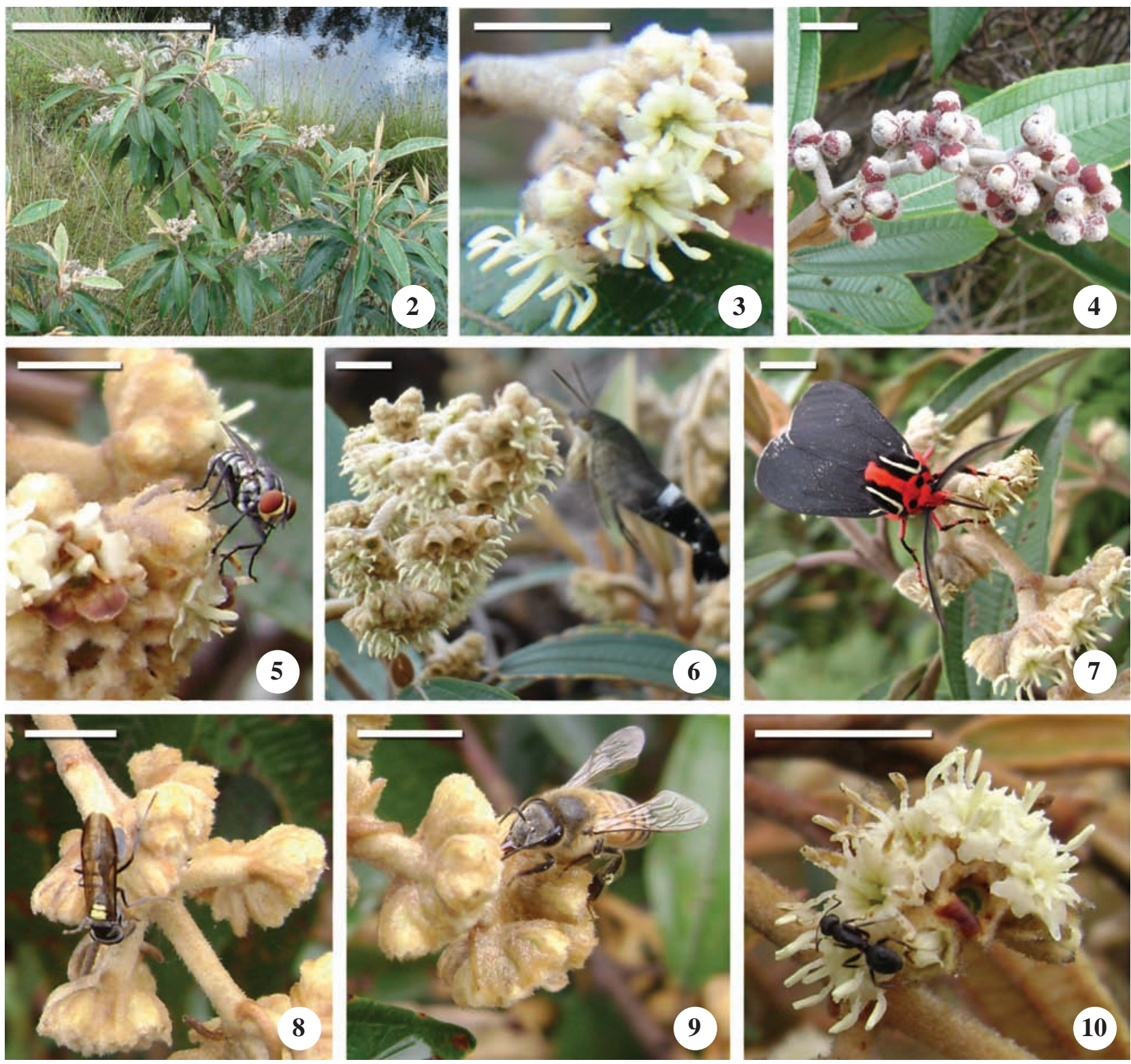

Figura 2-10. Miconia angelana. 2. Ramos floridos de indivíduo da população estudada. 3. Flores. 4. Frutos imaturos. 5-10. Visitantes florais. 5. Mosca. 6. Aellopos sp. (Sphingidae, mariposa-beija-flor). 7. Arctiidae. 8. Polistes sp. (vespa). 9. Apis mellifera. 10. Camponotus sp. Barra = $40 \mathrm{~cm}(2) ; 5 \mathrm{~mm}(3) ; 10 \mathrm{~mm}(4,5) ; 12 \mathrm{~mm}(6,7,9) ; 8 \mathrm{~mm}(8,10)$.

Figure 2-10. Miconia angelana. 2. Flowering branches of an individual of the studied population. 3. Flowers. 4. Immature fruits. 5-10. Floral visitors. 5. Flies. 6. Aellopos sp. (Sphingidae, hummingbird hawkmoth). 7. Arctiidae. 8. Polistes sp. (wasp). 9. Apis mellifera. 10. Camponotus sp. Bar = $40 \mathrm{~cm}(2) ; 5 \mathrm{~mm}(3) ; 10 \mathrm{~mm}(4,5) ; 12 \mathrm{~mm}(6,7,9) ; 8 \mathrm{~mm}(8,10)$.

formadas por autopolinização espontânea. A germinação das sementes do tratamento controle foi a mais lenta $(\bar{t}=22,28$ dias) e espalhada no tempo.

As sementes que não germinaram durante os 142 dias de experimento foram abertas e analisadas quanto à presença de embrião. As porcentagens de sementes vazias ou com embrião morto ou mal-formado foram próximas nos tratamentos de autopolinização manual e polinização cruzada. Cerca de $60 \%$ das sementes formadas nesses tratamentos não germinaram, principalmente por estarem vazias (figura 11).

O tratamento de autopolinização espontânea foi o que menos formou sementes estéreis. Das 150 sementes colocadas para germinar, 94\% possuíam embrião viável, os quais germinaram mais rapidamente e desenvolveram plântulas maiores (figura 12). 
Tabela 1. Porcentagem de frutificação, germinabilidade e tempo médio de germinação de sementes a partir de polinizações controladas em Miconia angelana.

Table 1. Percentage of fruition, germinability and average time of germination of seeds from controlled pollinations in Miconia angelana.

\begin{tabular}{lcccc}
\hline Tratamentos & № flores & $\begin{array}{c}\text { Frutificação } \\
(\%)\end{array}$ & $\begin{array}{c}\text { Germinação das } \\
\text { sementes } \\
(\%)\end{array}$ & $\begin{array}{c}\text { Tempo médio de } \\
\text { germinação } \\
\text { (dias) }^{1}\end{array}$ \\
\hline Autopolinização espontânea & 165 & 91,5 & $92,00 \pm 8,03 \mathrm{a}$ & $14,43 \pm 1,53 \mathrm{a}$ \\
Autopolinização manual & 151 & 33,1 & $20,00 \pm 5,27 \mathrm{c}$ & $17,70 \pm 1,26 \mathrm{a}$ \\
Polinização cruzada & 153 & 62,1 & $15,78 \pm 6,11 \mathrm{c}$ & $14,45 \pm 5,68 \mathrm{a}$ \\
Emasculação & 204 & 0,9 & - & - \\
Controle & 207 & 84,0 & $66,89 \pm 14,47 \mathrm{~b}$ & $22,28 \pm 10,26 \mathrm{~b}$ \\
\hline $\mathrm{W}(P)$ & & & $0,96(0,5976)$ & $\mathbf{0 , 8 0}(0,0006)$ \\
${ }^{2} \mathrm{~F}(P)$ & & & $1,57(0,236)$ & $2,98(0,0624)$ \\
${ }^{3} \mathrm{~F} / \mathrm{H}(P)$ & & $80,89(0,0001)$ & $12,15(0,0030)$ \\
\hline
\end{tabular}

Média \pm desvio padrão com letras iguais na coluna não diferem significativamente pelo teste de Tukey ou Dunn. ${ }^{1}$ Análise dos dados transformados para raiz(x). W: estatística do teste de Shapiro-Wilk; ${ }^{2} \mathrm{~F}$ : estatística do teste de Levene; ${ }^{3} \mathrm{~F}$ : estatística do teste de Snedecor (ANOVA); H: estatística do teste de Kruskal-Wallis (não paramétrico); $P$ : probabilidade. Valores em negrito indicam que os resíduos não seguem distribuição normal ou que não há homogeneidade entre as variâncias $(P>0,01)$.

Average \pm standard deviation with equal letters in the column doesn't differ significantly for the test of Tukey or Dunn. ${ }^{1}$ Analisis of the data transformed for $\operatorname{root}(\mathrm{x})$. W: statistics of the test of Shapiro-Wilk; ${ }^{2} \mathrm{~F}$ : statistics of the test of Levene; ${ }^{3} \mathrm{~F}$ : statistics of the test of Snedecor (ANOVA); H: statistics of the test of Kruskal-Wallis (distribution free); $P$ : probability. Values in boldface indicate that the residues don't follow normal distribution or that it doesn't have homogeneity between the variances $(P>0.01)$.

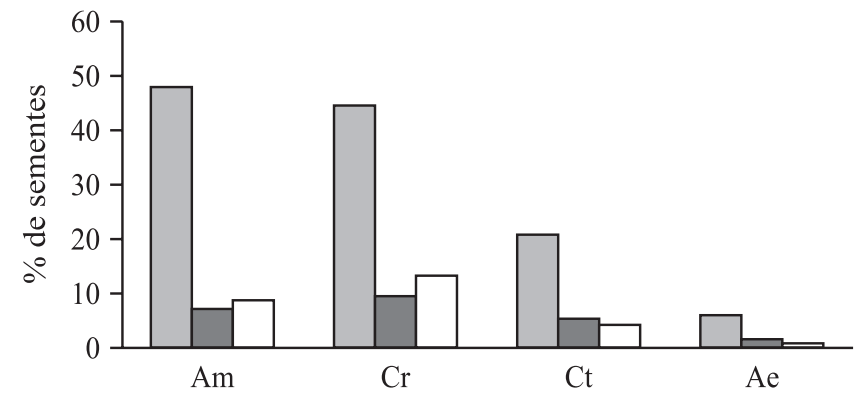

Figura 11. Caracterização das sementes de Miconia angelana que não germinaram durante o experimento. $($ Am $=$ autopolinização manual; $\mathrm{Cr}=$ polinização cruzada; $\mathrm{Ct}$ = controle; $\mathrm{Ae}=$ autopolinização espontânea; $\square$ = vazia; $\square=$ embrião morto; $\square=$ embrião mal formado).

Figure 11. Characterization of non germinated seeds of Miconia angelana. (Am: hand self-pollination; Cr: crosspollination; Ct: control; Ae: spontaneous self-pollination; $\square=$ empty; $\square$ = dead embryon; $\square=$ disease embryon).

\section{Discussão}

Miconia angelana pode ser considerada de floração precoce, pois floresce no começo das chuvas (Sarmiento \& Monasterio 1983). Floração sincrônica e de curta duração, intimamente relacionada com o início das

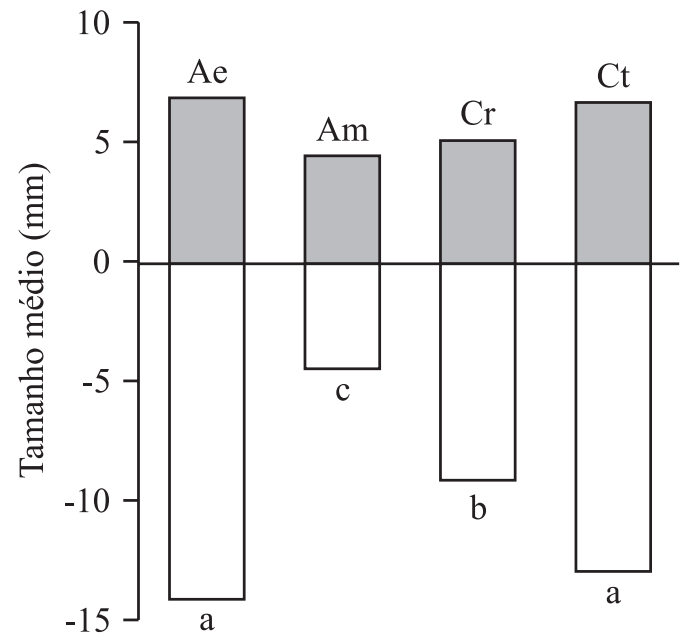

Figura 12. Crescimento inicial das plântulas de Miconia angelana. Resultados com letras diferentes diferem significativamente pelo teste de Tukey ou Dunn. (Ae = autopolinização espontânea; Am = autopolinização manual; $\mathrm{Cr}=$ polinização cruzada; $\mathrm{Ct}=$ controle; $\square=$ raiz primária; $\square=$ hipocótilo).

Figure 12. Initial growth of seedlings of Miconia angelana. Results with different letters differ significantly for the test of Tukey or Dunn. (Ae = spontaneous self-pollination; $\mathrm{Am}=$ manual self-pollination; $\mathrm{Cr}=$ cross-pollination; $\mathrm{Ct}=$ control; $\square=$ primary root; $\square=$ hypocotyl). 
chuvas, também é descrita para M. minutiflora (Bonpl.) DC. (Mori \& Pipoly 1984) e M. calvescens DC. (Meyer 1998). Porém, essas duas espécies apresentam floração mais sincrônica e limitada no tempo, referida na literatura como big bang, enquanto em M. angelana a floração apresenta múltiplos episódios ao longo de quase um mês, o que indicaria uma floração do tipo múltiplo bang (Gentry 1974).

A variedade de visitantes florais nas inflorescências de $M$. angelana é indício de que há produção de néctar. Mariposas e vespas visitam flores apenas para a coleta de néctar, sendo atraídos para $M$. angelana mesmo pelo pequeno volume e baixas concentrações de açúcares, cerca de $7 \%$ em $2 \mu \mathrm{L}$ de secreção, valor menor que o observado mesmo em outras espécies nectaríferas da família (14-20\%, Stein \& Tobe 1989).

Das 80 espécies de Melastomataceae relatadas como nectaríferas, apenas quatro pertencem ao gênero Miconia: M. sintenisii Cogn., M. minutiflora (Stein \& Tobe 1989), $M$. hyemalis e $M$. melanotricha (Triana) Gleason (Varassin com. pess.). Porém, nenhum dos trabalhos menciona análises de néctar, como volume e concentração de açúcares, dificultando, assim, as comparações. Para M. minutiflora é relatado apenas que há variação na produção de néctar e pólen entre os indivíduos da população estudada, o que aumentaria a visitação de polinizadores entre plantas e, portanto, a taxa de polinização cruzada (Mori \& Pipoly 1984).

O néctar em Melastomataceae é secretado por estômatos modificados presentes na epiderme dos estames (antera, apêndice ou conectivo), no hipanto ou no ápice do ovário (Varassin et al. 2008). A presença de nectários na família provavelmente é uma característica derivada, uma vez que espécies do mesmo grupo taxonômico, como as da tribo Blakeeae, apresentam nectários semelhantes (Varassin et al. 2008). Se confirmada essa hipótese, $M$. angelana deve apresentar nectários no ápice do ovário como em M. hyemalis, já que ambas pertencem ao grupo de espécies da seção Cremanium que ocorrem no Sudeste brasileiro (Goldenberg et al. 2008, Varassin et al. 2008). Estudos anatômicos serão importantes para comprovar tais características.

O odor forte e desagradável e a quantidade de moscas nas flores de $M$. angelana pode ser indício de polinização por esses insetos, o que foi relatado anteriormente apenas para M. pepericarpa (Goldenberg \& Shepherd 1998) e M. hyemalis (Varassin et al. 2008), aparentemente com as mesmas características reprodutivas e morfológicas mencionadas para M. angelana.

Ao contrário da maioria das espécies de Melastomataceae, onde predomina a xenogamia, flores de pólen e polinização vibrátil (Renner 1989), M. angelana é autógama e mais generalista quanto ao sistema de polinização. A presença de inflorescências densas, flores pequenas, anteras com poros grandes, produção de néctar podem ajudar a explicar a facilidade de polinização espontânea e a diversidade de polinizadores. Características semelhantes são encontradas em outras espécies de Miconieae, tornando-as mais generalistas quanto à guilda de polinizadores (Goldenberg \& Shepherd 1998).

A fecundação cruzada parece ser favorecida em M. angelana apenas pela diferença na velocidade de crescimento dos tubos polínicos. As flores de segundo dia autopolinizadas, por exemplo, provavelmente não formariam frutos, já que os tubos polínicos não terão tempo suficiente para crescerem e penetrarem o óvulo antes que a flor comece a murchar e o estilete caia. Em alguns casos este mecanismo pode funcionar como uma auto-incompatibilidade críptica, reduzindo endogamia (Eckert \& Allen 1997, Erbar \& Leins 1999, Erbar 2003). Mas de maneira geral a espécie é autocompatível e não apomítica. A possibilidade de apomixia via pseudogamia, como ocorre em outras plantas lenhosas de cerrado (Costa et al. 2004, Mendes-Rodrigues et al. 2005), não pode ser afastada. No entanto, a frequência de tubos polínicos e fertilizações nos pistilos resultantes de autoplonização espontânea indicam que a contaminação natural dos pistilos em inflorescências ensacadas é suficiente para explicar a frutificação obtida neste tratamento.

A formação de frutos a partir de autopolinização espontânea, mas sem apomixia, foi descrita apenas para quatro espécies de Melastomataceae: Miconia minutiflora (Goldenberg \& Shepherd 1998), M. sintenisii (Renner 1989), Rhynchanthera dichotoma (Desr.) DC. (Guimarães \& Ranga 1997) e Tibouchina papyrus (Pohl) Toledo (Santos 2003). A autogamia pode ser vantajosa por fixar genótipos importantes na população (Harder \& Wilson 1998, Barringer 2007, Williams 2007) de $M$. angelana do vale da nascente do rio São Francisco, único local de ocorrência da espécie.

Além da fixação de genes favoráveis na população, as espécies autógamas apresentam outras vantagens ecológicas, como a "segurança reprodutiva” (Richards 1986, Lloyd 1992) em ambientes com populações pequenas, como as de $M$. angelana, ou em períodos de ausência ou baixa frequência de polinizadores, o que dificultaria a polinização cruzada.

Entretanto, há custos como o desconto de gametas (Lloyd 1992, Harder \& Wilson 1998), ou seja, pólen que poderia ser utilizado na fecundação cruzada é gasto com a autofecundação “roubando” óvulos que poderiam 
ser fecundados com pólen de outros indivíduos. A alta frequência de autopolinização, seja por autogamia, geitonogamia ou autopolinização biparental (polinização entre indivíduos aparentados), também pode resultar em depressão endogâmica, caso haja genes deletérios na população (Richards 1986, Lloyd 1992, Barringer 2007, Williams 2007).

O tratamento com maior porcentagem de frutificação, autopolinização espontânea, também produziu as sementes com maior germinabilidade e plântulas com maior crescimento inicial. É possível que a manipulação das flores, durante os tratamentos de polinizações controladas, tenha sido o principal motivo para o desencadeamento de reações abortivas ao longo do desenvolvimento dos frutos e para a formação de muitas sementes estéreis, o que explicaria, respectivamente, a baixa frutificação e a baixa germinabilidade das sementes formadas nesses tratamentos. Diferentemente de $M$. angelana, nas espécies de Melastomataceae com frutificação por autopolinização espontânea (Renner 1989, Guimarães \& Ranga 1997, Goldenberg \& Shepherd 1998, Santos 2003), a manipulação das flores não induziu maiores taxas de aborto dos frutos, visto que em geral, a polinização cruzada produziu mais frutos que os demais tratamentos.

Salvo os problemas de inviabilidade das sementes de $M$. angelana, a germinação foi rápida e não houve dormência. A estratégia de germinação das sementes é um pouco diferente, tanto das espécies de ambientes florestais (Zaia \& Takaki 1998, Baskin et al. 1999, Valio \& Scarpa 2001) quanto de ambientes abertos como os campos rupestres (Ellison et al. 1993). Como a floração ocorre no início da estação chuvosa, os frutos carnosos amadurecem rapidamente e as sementes são liberadas ainda durante a abundância de água, não apresentando dormência.

Goldenberg \& Shepherd (1998) observaram certa relação entre o sistema reprodutivo e a distribuição geográfica de algumas espécies do gênero Miconia, na qual espécies apomíticas seriam supostamente de distribuição mais ampla que outras sexuadas, com distribuição mais restrita. $\mathrm{O}$ estudo da biologia reprodutiva de $M$. angelana vem corroborar essa hipótese, por se tratar de uma espécie endêmica com população de tamanho limitado, mas onde a reprodução, apesar de basicamente autogâmica, parece ser estritamente sexuada.

O conhecimento da biologia reprodutiva de espécies raras ou com distribuição restrita a determinada região é o primeiro passo para a sua conservação (Kaye 1999, Bernardello et al. 1999, Vieira \& Grabelos 2003). Caso essas espécies, assim como M. angelana, não se reproduzam assexuadamente, o estabelecimento de novos indivíduos na população depende do sucesso na polinização e na dispersão de diásporos em locais apropriados. Aflexibilidade reprodutiva possibilitada pelas flores relativamente generalistas em termos de polinização e pela autogamia provê a segurança reprodutiva para a manutenção da população estudada. Estas características evitam falhas no ciclo reprodutivo que poderiam levar espécies endêmicas, como $M$. angelana, ao risco de extinção (Vieira \& Grabelos 2003).

Agradecimentos - Ao Conselho Nacional de Pesquisa Científica (CNPq) pelo financiamento do projeto (Processo 371970/2006-7), ao Ibama pela concessão da licença para pesquisa, ao Joaquim Maia Neto, diretor do Parque Nacional da Serra da Canastra, pela estadia em sua casa e facilidades proporcionadas no Parque, à Dra. Marli Ranal e ao Msc. Clesnan Rodrigues pela valiosa ajuda nos experimentos de germinação a Cauê Thomé Lopes, pela identificação da formiga, Felipe Wanderley Amorim, das mariposas, a Alice Maria Guimarães Fernandes Vilhena pela confirmação da identificação da abelha e aos amigos Eric Hattori e Priscila Oliveira Rosa, pela ajuda imprescindível nas atividades de campo.

\section{Referências bibliográficas}

BARRINGER, B.C. 2007. Polyploidy and self-fertilization in flowering plants. American Journal of Botany 94:15271533.

BASKIN, C.C., BASKIN, J.M. \& CHESTER-EDWARD, W. 1999. Seed dormancy and germination in Rhexia mariana var. interior (Melastomataceae) and ecoevolutionary implications. Canadian Journal of Botany 77:488-493.

BERNARDELLO, G., ANDERSON, G.J., LOPEZ, S.P., CLELAND, M.A., STUESSY, T.F. \& CRAWFORD, D.J. 1999. Reproductive biology of Lactoris fernandeziana (Lactoridaceae). American Journal of Botany 86:829840.

BUCHMANN, S.L. 1983. Buzz pollination in Angiosperms. In Handbook of experimental pollination biology (C.E. Jones \& R.J. Little, eds.). Van Nostrand Reinhold, New York, p.73-113.

BULLOCK, S.H. 1985. Breeding systems in the flora of a tropical deciduous forest. Biotropica 17:287-301.

CLAUSING, G. \& RENNER, S.S. 2001. Molecular phylogenetics of Melastomataceae and Memecylaceae: implications for character evolution. American Journal of Botany 88:486-498.

COSTA, M.E., SAMPAIO, D.S., PAOLI, A.A.S. \& LEITE, S.C.A.L. 2004. Polyembriony and aspects of embryogenesis in Tabebuia ochracea (Chamisso) Standley (Bignoniaceae). Revista Brasileira de Botânica 27:395-406. 
ECKERT,C.G.\&ALLEN,M.1997.Crypticself-incompatibility in tristylous Decodon verticillatus (Lythraceae). American Journal of Botany 84:1391-1397.

ELLISON, A.M., DENSLOW, J.S., LOISELLE, B.A. \& BRENÉS, D.M. 1993. Seed and seedling ecology of neotropical Melastomataceae. Ecology 74:1733-1749.

ERBAR, C. 2003. Pollen tube transmitting tissue: place of competition of male gametophytes. Internacional Journal of Plant Sciences 164:265-277 (supplement).

ERBAR, C. \& LEINS, P. 1999. Secondary pollen presentation and a curious rupture of the style in Spigelia (Spigeliaceae, Gentianales). Plant Biology 1:389-402.

FRACASSO, C.M. \& SAZIMA, M. 2004. Polinização de Cambessedesia hilariana (Kunth) DC. (Melastomataceae): sucesso reprodutivo versus diversidade, comportamento e freqüência de visitas de abelhas. Revista Brasileira de Botânica 27:797-804.

GENTRY, A. 1974. Coevolutionary patterns in Central American Bignoniaceae. Annals of the Missouri Botanical Garden 61:728-759.

GOLDENBERG, R. 2000. O gênero Miconia Ruiz \& Pav. (Melastomataceae): I. Listagens analíticas, II. Revisão taxonômica da seção Hypoxanthus (Rich. ex DC.) Hook. f. Tese de doutorado, Universidade Estadual de Campinas, Campinas.

GOLDENBERG, R., PENNEYS, D.S., ALMEDA, F., JUDD, W.S. \& MICHELANGELI, F.A. 2008. Phylogeny of Miconia (Melastomataceae): patterns of stamen diversification in a megadiverse neotropical genus. International Journal of Plant Sciences 169:7963-7979.

GOLDENBERG, R. \& SHEPHERD, G.J. 1998. Studies on the reproductive biology of Melastomataceae in "cerrado" vegetation. Plant Systematics and Evolution 211:13-29.

GOLDENBERG, R. \& VARASSIN, I.G. 2001. Sistemas reprodutivos de espécies de Melastomataceae da Serra do Japi. Revista Brasileira de Botânica 24:283-288.

GUIMARÃES, P.J.F. \& RANGA, N.T. 1997. Sistema de reprodução de Rhynchanthera dichotoma (Lam.) DC. Acta Botanica Brasilica 11:41-44.

HARDER, L.D. \& WILSON, W.G. 1998. A clarification of pollen discounting and its joint effects with inbreeding depression on mating system evolution. American Naturalist 152:684-695.

KAYE, T.N. 1999. From flowering to dispersal: reproductive ecology of an endemic plant, Astragalus australis var. olympicus (Fabaceae). American Journal of Botany 86:1248-1256.

KEARNS, C.A. \& INOUYE, D.W. 1993. Techniques for pollination biologists. Colorado University Press, Niwot.

LABOURIAU, L.G. 1983. Agerminação das sementes. Série de Biologia. Monografia 24. Secretaria Geral da Organização dos Estados Americanos - OEA, Washington.

LLOYD, D.G. 1992. Self- and cross-fertilization in plants. II. The selection of self-fertilization. International Journal of Plant Sciences 151:370-380.
LUMER, C. 1980. Rodent pollination of Blakea (Melastomataceae) in a Costa Rican Cloud Forest. Brittonia 32:512-517.

LUMER, C. \& SCHOER, R.D. 1986. Pollination of Blakea austin-smithii and B. penduliflora (Melastomataceae) by small rodents in Costa Rica. Biotropica 18:363-364.

MARTIN, F.N. 1959. Staining and observation pollen tubes in the style by means of fluorescence. Stain Technology 34:125-128.

MELO, G.F., MACHADO, I.C. \& LUCEÑO, M. 1999. Reprodución de tres especies de Clidemia (Melastomataceae) en Brasil. Revista de Biología Tropical 47:359-363.

MENDES-RODRIGUES, C., CARMO-OLIVEIRA, R., TALAVERA, S., AISTA, M., ORTIZ, P.L. \& OLIVEIRA, P.E. 2005. Polyembriony and apomixis in Eriotheca pubescens (Malvaceae - Bombacoideae). Plant Biology 7:533-540.

MEYER, J. 1998. Observations on the reproductive biology of Miconia calvescens DC (Melastomataceae), an alien invasive tree on the island of Tahiti (South Pacific Ocean). Biotropica 30:609-624.

MMA/IBAMA. 2005. Plano de manejo - Parque Nacional da Serra da Canastra. Ministério do Meio Ambiente - MMA/Instituto Brasileiro do Meio Ambiente e dos Recursos Naturais Renováveis - Ibama, Brasília.

MORI, S.A. \& PIPOLY, J.S. 1984. Observations on the big bang flowering of Miconia minutiflora. Brittonia 36:337-341.

OLIVEIRA, P.E. \& GIBBS, P.E. 2000. Reproductive biology of woody plants in a cerrado community. Flora 195:311329.

PROENÇA, C. 1992. Buzz pollination - Older and more widespread than we think? Journal of Tropical Ecology 8:115-120.

RADFORD, A.E., DICKINSON, W.C., MASSEY, J.R. \& BELL, C.R. 1974. Vascular plant systematics. Harper \& Row Publishers, New York.

RANAL, M. \& SANTANA, D.G.D. 2006. How and why to measure the germination process? Revista Brasileira de Botânica 29:1-11.

RENNER, S.S. 1989. A survey of reproductive biology in Neotropical Melastomataceae and Memecylaceae. Annals of the Missouri Botanical Garden 76:496-518.

RICHARDS, A.J. 1986. Plant breeding systems. Allen \& Unwin, London.

ROMERO, R. \& GOLDENBERG, R. 1999. A new species of Miconia (Melastomataceae) from Serra da Canastra National Park, Minas Gerais, Brazil. Novon 9:98-100.

ROMERO, R. \& MARTINS, A.B. 2002. Melastomataceae do Parque Nacional da Serra da Canastra, Minas Gerais, Brasil. Revista Brasileira de Botânica 25:19-24.

ROMERO, R. \& NAKAJIMA, J.N. 1999. Espécies endêmicas do Parque Nacional da Serra da Canastra, Minas Gerais. Revista Brasileira de Botânica 22:259-265. 
SANTOS, M.L. 2003. Florística e biologia reprodutiva de espécies de Melastomataceae no Parque Estadual da Serra de Caldas Novas e Parque Estadual dos Pirineus, Goiás. Tese de doutorado, Universidade de Brasília, Brasília.

SARMIENTO, G. \& MONASTERIO, M. 1983. The savannas of tropical América. In Ecosystems of the world: tropical savannas (F. Bouliere, ed.). Elsevier, Amsterdam, p.245-288.

STEIN, B.A. \& TOBE, H. 1989. Floral nectaries in Melastomataceae and their systematic and evolutionary implications. Annals of the Missouri Botanical Garden 76:519-531.

VALIO, I.F.M. \& SCARPA, F.M. 2001. Germination of seeds of tropical pioneer species under controlled and natural conditions. Revista Brasileira de Botânica 24:79-84.
VARASSIN, I.G., PENNEYS, D.S. \& MICHELANGELI, F.A. 2008. Comparative anatomy and morphology of nectar-producing Melastomataceae. Annals of Botany 102:899-909.

VIEIRA, M.F. \& GRABELOS, R. 2003. Sistema reprodutivo de Oxypetalum mexiae Malme (Asclepiadaceae), espécie endêmica de Viçosa, MG, Brasil, em perigo de extinção. Acta Botanica Brasilica 17:137-145.

WILLIAMS, C.F. 2007. Efects of floral display size and biparental inbreeding on outcrossing rates in Delphinium barbeyi (Ranunculaceae). American Journal of Botany 94:1696-1705.

ZAIA, J.E. \& TAKAKI, M. 1998. Estudo da germinação de sementes de espécies arbóreas pioneiras: Tibouchina pulchra Cogn. e Tibouchina granulosa Cogn. Acta Botanica Brasilica 12:227-238. 